\title{
TOWARDS AN ADVANCED CONSERVATION STRATEGY: A STRUCTURED DATABASE FOR SHARING 3D DOCUMENTATION BETWEEN EXPERT USERS.
}

\author{
C. Achille ${ }^{1}$, C. Tommasi ${ }^{1 *}$, F. Rechichi ${ }^{1,2}$, F. Fassi ${ }^{1}$, E. De Filippis ${ }^{3}$ \\ ${ }^{1} 1$ Dept. of Architecture, Built environment, and Construction engineering (ABC), Politecnico di Milano, Milano, IT - \\ (cristiana.achille; cinzia.tommasi; fabrizio.rechichi; francesco.fassi)@polimi.it \\ ${ }^{2}$ Dept. of Ingegneria e Architettura, Università degli studi di Parma, Parma, IT - fabrizio.rechichi@studenti.unipr.it \\ ${ }^{3}$ Ente di Gestione dei Sacri Monti, Sacro Monte di Varallo, Vercelli, IT - direttore@sacri-monti.com
}

Commission II, WG II/8

KEY WORDS: Unesco Sites, Digitalisation, Conservation, Valorisation, CDE, Web Database

\begin{abstract}
:
Nowadays, the researchers in Cultural Heritage fields investigate more and more about advanced conservation strategies that comprehend the possibility to share and use 3D models and structured information related to them. One of the modern method adopted to achieve this goal is to use structured web-platform. These are online systems that can handle data, created to contain and support precise information. They simultaneously respond to the need for a "common" ground for different expert users and of a unique tool where to store several kinds of data, coming from heterogeneous sources. The article aims to show how it is possible to build a valid tool for the conservation and monitoring activities of $\mathrm{CH}$, following the national and international legislation and the specific needs of the application field. In particular, it will deepen the criteria to build a 3D model that has to link a database of information, specifying the logic behind it. In the same way, it will show how to structure a database collaborating with the local institutions and experts, following the real needs of the site. The benefit is that this kind of tools gives to the multi-disciplinary works and projects a shared environment for storing and view a different type of data. They can help both the access intended to the conservation activities and both they can open to the public. The application field is the Sacri Monti circuit, which is part of the UNESCO World Heritage List since 2003.
\end{abstract}

\section{INTRODUCTION}

How is it possible to measure and monitor the needs of a Cultural Heritage site and build an efficient tool useful for its conservation?

The article's case study referred to Sacri Monti, which are described in their official website as "The nine Sacri Monti of Northern Italy are groups of chapels and other architectural edifices constructed in the 16th and 17th centuries, dedicated to different aspects of the Christian faith [...] and they are integrated in natural and scenic environments of hills, woods and lakes. They also contain significant artistic remains (frescoes and statues)". In 2003 UNESCO registered the site "Sacri Monti of Piedmont and Lombardy" in its World Heritage List, demonstrating their correspondence with the parameter of Outstanding Universal Value (OUV ${ }^{1}$ ) and two ${ }^{2}$ (Criterion II and $\mathrm{IV}^{3}$ ) of the ten selection Criteria of the World Heritage Committee, associated also with the extra evaluations about authenticity, integrity, and conservation state ${ }^{4}$. This condition gives to the site a recognisable national and international identity,

1 OUV Outstanding Universal Value (UNESCO, 2005, Operational Guidelines) Par. 49. Outstanding universal value means cultural and/or natural significance, which is so exceptional as to transcend national boundaries and to be of common importance for present and future generations of all humanity. As such, the permanent protection of this heritage is of the highest importance to the international community as a whole. The Committee defines the criteria for the registration of properties on the World Heritage List.

2 The selection criteria are the parameters to consider in the phase of enlisting a $\mathrm{CH}$ in UNESCO WHL. To be included, and for this reason, it is subjected to Italian law (Codice dei Beni Culturali e del Paesaggio, 2004) and UNESCO parameters and criteria (indicated in Operational Guidelines for Implementation of the World Heritage Convention) to stay in the list. In particular, they are subjected to the drafting of Periodic Reporting, which is one of the core conservation monitoring mechanisms of the World Heritage Convention, and a track for the needs of the site.

The objective of the research presented is to focus on the report, proposing a tool based on the specific needs of the site for planning and storing the conservation activities. The work suggests an interdisciplinary pipeline, which involved the institutions and different kind of experts from the early stage of design (university, technical office, restorers, and others).

Thanks to the PR it is possible to measure and monitor every six years the needs of the Sacri Monti circuit, which comprehend the management of conservation activities, and to design a flexible solution fitted on the real demands. In this case, the system proposed is BIM3DSG (Fassi et al., 2012; Rechichi et al., 2016), which involves the use of reality-based 3D models of the chapels

sites must be of outstanding universal value and meet at least one out of ten selection criteria. (UNESCO, 2005, Operational Guidelines)

3 C(ii): "to exhibit an important interchange of human values, over a span of time or within a cultural area of the world, on developments in architecture or technology, monumental arts, town-planning or landscape design".

C(iv): "to be an outstanding example of a type of building, architectural or technological ensemble or landscape which illustrates (a) significant stage(s) in human history".

4 Document of Selection of Sacri Monti, UNESCO, 2003. 
linked to a Data Base (DB) of information. The latter is designed collaborating with the local institutions and experts with different skills and backgrounds, following the real needs of the site. The user interface to visualise the models and information is a web browser, which is usable from anyone without installing specific software, and it represents a shared environment for storing and viewing different type of data.

The result of the work will help to update a section of the next UNESCO’s Periodic Reporting (2018-2024) and will contribute to shaping "standard" best practices to monitor and safeguard Sacri Monti complex and all the similar case studies.

\subsection{Communication and target}

The conservation and the preservation of $\mathrm{CH}$ are part of the strategic lines to adopt for its valorisation, both at national and international heritage (MIBACT 2004; COE 2005; UNESCO 2005).

In an environment where many actors play (public institutions, different kind of experts, stakeholders, local communities, tourists, and more) the first obstacle to overcome is the communication between them, and the use of advanced technologies permits to better manage the quality and the quantity of information in every stage of the project (Della Torre, 2014). It is clear that according to the target and the context of the message, the topics, style, and tools of communication change (Table 1).

\begin{tabular}{|l|l|l|l|}
\hline Context & $\begin{array}{l}\text { Research } \\
\text { Target }\end{array}$ & Management & Transmission \\
\hline Topic & $\begin{array}{l}\text { Experts } \\
\text { Scientific } \\
\text { data }\end{array}$ & $\begin{array}{l}\text { Muthorities } \\
\text { data }\end{array}$ & $\begin{array}{l}\text { Non-experts } \\
\text { daterpretation } \\
\text { of Cultural } \\
\text { Value }\end{array}$ \\
\hline Style & $\begin{array}{l}\text { Scientific } \\
\text { and } \\
\text { objective }\end{array}$ & $\begin{array}{l}\text { Objective } \\
\text { and detached }\end{array}$ & $\begin{array}{l}\text { Subjective } \\
\text { and } \\
\text { involving }\end{array}$ \\
\hline Tools & Web platform BIM3DSG & $\begin{array}{l}\text { Immersive } \\
\text { and } \\
\text { educational } \\
\text { experiences }\end{array}$ \\
\hline
\end{tabular}

Table 1. According to the target and the context of communication, the style and the tools change. In dashed lines, the focus area of the article. Source: re-elaboration from Negrini, 2015.

The context of the article is research and management, and the target of the users and collaborators is experts and public authorities. The researchers of Politecnico di Milano intensely collaborated with Ente di Gestione dei Sacri Monti, the body that manages the seven Sacri Monti of Piedmont. They helped to define the information database behind the 3D models, to test the platform, and to model the digital model of the buildings (mainly the chapels) after a training period. In this case, the communication has to be objective, to connect expert people with different backgrounds. The type of information regards scientific and management data (e.g. preservation and restoration data, decay, materials, point clouds, and more), manageable through the web platform BIM3DSG.

5 The 1972 Convention concerning the Protection of the World Cultural and Natural Heritage has been a key instrument in heritage conservation in every region of the world. The Convention has been ratified by 190 out of the 193 Member States of UNESCO, and its World Heritage List comprises 936 properties (as of 1 January 2012). The States Parties to the

\section{APPLICATION FIELD AND UNESCO PERIODIC REPORTING}

\subsection{Application field}

A «Sacro Monte» is a devotional path inserted in an isolated and beautiful landscape. The chapels and the church that compose the path contain inside artistic scenes (made by statues, paintings, and others) that evoke the theme described (Tommasi et al.,2019).

The phenomenon of Sacri Monti began at the turn of the 15th and 16th centuries to create in Europe places of prayer as an alternative to the Holy Places in Jerusalem and Palestine, access to which was becoming more difficult for pilgrims owing to the rapid expansion of Muslim culture. The first was built in 1480 in Varallo, Piedmont. During the $17-18^{\text {th }}$ others succeed at Crea, Orta, Varese, Oropa, Ossuccio, Ghiffa, Domodossola, and Valperga. Although at the outset, these followed specific basic rules, as they were being constructed, they developed individual artistic and architectural aspects.

One of the needs of "Sacri Monti" Circuit and objective of the work are to find a method to manage the ordinary maintenance activities of the chapels, which comprehend cleaning, substitution, decay analyses, interventions, and more. In this environment, many people with different competencies, skills, and education have to collaborate, and for this reason, they need a unique platform where to collect their interventions, analyses, and information. The advantage to working on a UNESCO site is that it is possible to understand its specific issues and action plans through the Periodic Reporting system, using it as a base for developing a solution specific for this site but adjustable to others. Also, the PR works on two different scales aiming both to promote regional collaboration and both to respond to the specific characteristics of the sites.

\subsection{UNESCO Periodic Reporting}

UNESCO defines Periodic Reporting ${ }^{5}$ as one of the core conservation monitoring mechanisms of the World Heritage Convention. It provides an assessment of its application by the States Parties, facilitates the update of information on the World Heritage properties and records possible changes in their state of conservation. This process enables the formulation of strategies for reinforcing the capacities of States Parties and developing more sustainable conservation mechanisms for their World Heritage properties.

Every six years, on a rotating basis by Region, the States Parties must submit to the World Heritage Committee a Periodic Report on the application of the World Heritage Convention in their territory (UNESCO, 2012).

In particular, the main objectives of PR are:

- $\quad$ assessing the state of conservation of the properties;

- determining if the Outstanding Universal Value OUV is maintained over time;

- $\quad$ sharing experiences, good practices, knowledge and lessons learnt between State Parties, Site Managers and other practitioners;

- $\quad$ providing a decision-making tool;

- $\quad$ raising awareness about the WH Convention.

Convention, by joining hands to protect and cherish the world's natural and cultural heritage, express a shared commitment to preserving our legacy for future generations. Sites inscribed on the World Heritage List benefit from being part of an international network and having access to technical advice on adequate preservation measures and monitoring mechanisms. 
The report becomes the baseline for the development of an Action Plan at national and regional levels which will respond to the needs, challenges, threats, strengths and opportunities identified and presented as a result of the Periodic Reporting. The process lasts approximately six years, and it works at a regional level ${ }^{6}$ and is divided into five steps: i) reporting in regions, where the National Focal Points complete a state-level questionnaire (section I) while each World Heritage property in the region complete another one about the site (section II); ii-iii) the reports are sent to WHC, which exanimate them, and formulate some recommendations; iv) regional action plans are created for setting strategies, priorities and goals for implementation of WHC; v) State Parties implement Action Plans and recommendations for the local reports.

Section II of the report and the action plan documents are valuable tools to understand the issues that affect the site, and to know the strategy to follow to solve them.

\subsubsection{Sacri Monti PR II ${ }^{\circ}$ Cycle (2008-2015)}

As mentioned above, the Periodic Report is composed of two sections (I and II), in the form of a questionnaire, compiled by World Heritage Site Manager (section II) and the National Focal Point (section I and validating section II). The first lists the State Party, the institutions, and groups involved in the preparation of the Report; the second provides information about the primary data of the property and its management.

The document contains a series of criteria through which to assess the 'health status' of the Sacri Monti. The factors evaluated are properties, buildings, transportation infrastructures, services, local conditions, social/cultural uses of heritage, conservation, monitoring, and others.

In particular, the categories represented in the Periodic Report Second Cycle (2012-2015 for Europe) highlight the parameters considered for the conservation and valorisation of the site, which are divided into three macro-categories: i) management system/management plan, ii) education, information, and awareness building, and iii) monitoring. The main issues are no awareness of the property by residents, no annual work/action plan, no education awareness program, some tourists monitoring but not planned.

The issues highlighted in the local document of Sacri Monti and the others belonging to the European region help the WHC to write the final report on the results and Action Plan of Second cycle of the Periodic Reporting exercise for Europe. It is interesting to notice that the main objectives are: identification and protection of OUV, effective management of WH properties, increased awareness of the convention. Each of these goals is divided into priority areas, which recalls the issues founded in Sacri Monti Report. The action framework in the management system section aims to a regular monitoring system using the PR outcomes, the State of Conservation Data Base, as well other existing tools, aspiring to have the $100 \%$ of properties with a regular monitoring process by the next PR (Third Cycle 20182024). Moreover, another action framework is to present and interpret PR results and take appropriate management actions at national and site levels, working towards an outcome where $100 \%$ of the properties employ the PR as a valid tool for apply them.

The issues and the strategies highlighted by these documents are the basis of the research work presented below, trying to develop a conservation and monitoring system usable from many experts with different skills and backgrounds, and applicable to many

${ }^{6}$ The five regions for PR are: Arab States, Africa, Asia and the Pacific, Latin America and the Caribbean, and Europe and North America. sites, changing the features according to the specificity of the application field.

\section{SACRI MONTI WEB SYSTEM}

The possible strategies to adopt to answer specific tasks of management and conservation of Sacri Monti from the Periodic Reporting process are many. The research in progress proposes a tangible and flexible tool, a web-based platform BIM3DSG which lets to:

- loading, visualisation and use of 3D models inside an ordinary web browser, selecting the level of detail desired;

- $\quad$ updating in real-time the work's progress;

- monitoring the conservation state of Sacri Monti;

- planning the intervention of restoration and conservation;

- managing the information system;

- $\quad$ using the system in portable devices;

- $\quad$ sharing data among experts.

Therefore, the research lines to explore regard, on the one hand, the construction of the digital model of the chapels of different Sacri Monti, as they are subjected to continuous conservation interventions, and on the other side, the development of the database related, from admin and users point of you, showing the structure and the logic of the system. All the project is currently carried out in a co-working and co-creation perspective, in fact, the researchers strictly collaborate with Ente di Gestione dei Sacri Monti in the building, testing, and use of the tool proposed.

\subsection{Modelling phase}

The BIM3DSG platform works with 3D models and survey data (as point clouds), in fact, it links to them the Data Base of information created ad hoc. For this reason, before presenting the web interface (users), it is necessary to understand how to build the digital support of the DB. The starting assumption is to have a complete and accurate geometrical description of the objects represented, so the work starts with data acquisition through survey campaign (laser or mobile scanner, terrestrial and aerial photogrammetry) or from collecting the existing data provided by Ente di Gestione as bi-dimensional drawings (CAD format). The geometric surveys available were sufficient for an overall lecture of the buildings and made possible the elaboration of a three-dimensional model. This survey output has to respect some criteria, derived by the needs of Sacri Monti: i) the division of the digital model in each of its constitutive element; ii) the fast achievement of a complete result; iii) the interpretation of the geometries; iv) the geo-localisation of the objects in world coordinates. As mentioned above, the models have to represent the Chapels correctly and to support the information about the regular monitoring and conservation activities of the Ente. For this reason, it must be possible to visualise and link the information related to the structural, material, decay, and others analyses every single element of the historic building. The first aim of the model and the system is to be used in the daily monitoring activities of the chapels.

The technique chosen was the parametric object-oriented modelling, which is peculiar of Building Information Modelling software. The BIM model becomes a richness: its employment is supported more and more by national (UNI11337, 2017) and international regulations, it has great potentialities for connecting 
the 3D model with an entire information system, and it can support the management of the whole life cycle of the building. For the modelling phase, a set of spot chapels were selected according to Ente di Gestione dei Sacri Monti, as "pilot" example of the work. Each of these objects had different locations, problems, and needs. It was essential to set the work thinking beyond the spot chapels, and considering the multi-scale feature of the sites: the regional level made by seven Sacri Monti of Piedmont, the local level where each Sacro Monte has a different number of chapels, problems, and peculiarities, and the level of the single chapel, divided into all its constitutive parts. One of the visualisation goals concerning the local level was to correctly geo-reference the chapels between each other.

On the other hand, at the level of single buildings, the criterion for modelling was the description of the model in all the parts necessary to link the punctual information about conservation and management. It was required to know and select before the data to assign to the 3D model to do this operation. The information currently used about the conservation activities are:

- Roofs sheets

- Humidity analyses

- $\quad$ Static damages

- $\quad$ Restorers' knowledge about the statues

What matters in this specific case, the division of the model in all the constitutive parts is necessary to reference the information related to the conservation activities easily.

All the elements are described according to the data at disposal (DWG format and point cloud data), becoming a compromise between geometric description, quality (accuracy), modelling time and information adding.

It is essential to think carefully about the correct interpretation and representation of the pieces and the categories of the objects because what matters next is the massive quantity of information. The preparatory step to the modelling phase was the study of the architectonical system of the Chapels, which is organised in different elements. This de-constructing step was mandatory because the information listed above about the conservation activities are referred to the specific objects, or group of objects, or surfaces that compose the buildings, so it is necessary that the model reproduces this sub-division. In this way, the division happens both for macro categories of elements, and both for single parts: e.g. the portico as a whole, and the separate columns that compose it. The structure of the BIM software used helped to carry out this discrimination process, thanks to the objectoriented method that creates objects from libraries of real elements (as doors, walls, and more).

This workflow was also transmitted to the technical office of Ente di Gestione dei Sacri Monti through a training session, to make them able to continue the modelling of all the chapels of the seven Sacri Monti. In fact, in addition to the advantages that BIM techniques offer, it is essential to underline that this kind of models can serve different usages thanks to the possibility to export in various formats like IFC, OBJ, FBX and more. Thus, the BIM model passes from being editable only from BIM specialists to an open system to be usable from every kind of expert. The figures and professionals that work on these kinds of data are many, skilled and non-skilled in using 3D modelling software (the technician, the restorer, the Head of Ente, and others). For this reason, to connect them all, the research proposed an online platform to manage the conservation activities: all the different kind of expert users can access to the data and the 3D models (imported inside BIM3DSG in OBJ format).

The next phase is to understand how to build the common ground to connect all the specialists able to display the multi-sensor survey data and the model together, and what kind of information has to match the objects.

\subsection{Sharing Phase: accessing to 3D models and the ad-hoc Data Base}

The online platform is a more flexible and accessible tool than a BIM or modelling software: in fact, it is possible to manage and easily visualise an information database, share the models and their content between experts with different skills, manage the conservation activities, enhance the survey data and their outputs. The benefit of BIM3DSG system is the possibility to shape it according to the need of the case study. It is based on PostgreSQL, a "free database management system" developed through Pgadmin software. Thanks to this feature the Data Base (DB) has a "fixed infrastructure" that is possible to customise time by time through the creation of different fields based on the necessities of the case study. These fields can be structured through administrative operations of rows filling.

The interface and the functionalities are not the results of the elaboration of a single person, but it is a group work where it is necessary to involve not only the developers but also the final customers (in this case, the technical office of Ente di Gestione dei Sacri Monti) in a co-design process (Mattelmäki et al., 2011). Thanks to the teamwork, the result is accurate and fitted on the real needs of the chapels.

The first phase regarded the editing and customisation of the DB, which was necessary to make data visible in the web interface. It was required to analyse the content of the sheets related to the conservation activities, e.g. the ones of the roofs or the statues, and to evaluate together with the Ente what and how many fields were mandatory to insert inside a model. These sheets are the basis that they use for these activities, so it was necessary to identify recursive data, problems, and evaluation criteria common to all the conservation interventions, and synthesise them. This study was useful for avoiding errors and free interpretation of the phenomenon, and for having a unique vocabulary without an incremental number of terms inside the DB.

Once the fields and the terms to list were individuated, it was necessary to organise them at informatic level, following the BIM3DSG logic of DB structure and relationships between information, which derives from long discussions and reflections with Ente di Gestione, to select and arrange the information required to manage the conservation activities.

This is the system's architecture:

- the objects modelled are labelled as categories that represent the $3 \mathrm{D}$ components division, and refer to classes of real elements (e.g. roofs, columns, windows, and others); The objects' categories are connected to the DB through relationships that can be one to one, one to many, or many to one;

- the DB is designed in three classes of information:

o object info, which is the data connected to the object that does not change in time (e.g. the geographic localisation - region, site, and more);

o version info, which represents the data referred to a new 3D model that substitute the original one during the time;

o subversion info, when the 3D model does not change during the time, only the information related to it is updated.

The latter two types permit to trace the operations and inspections already made or in progress in the buildings (chapels), handling their life-cycle and planning the events through time;

Each class of information has different customised macro fields, and each macro field has specific "rows" inside it (Figure 1). In this way, it is possible to insert both general information (macro fields) and detailed information (rows). 


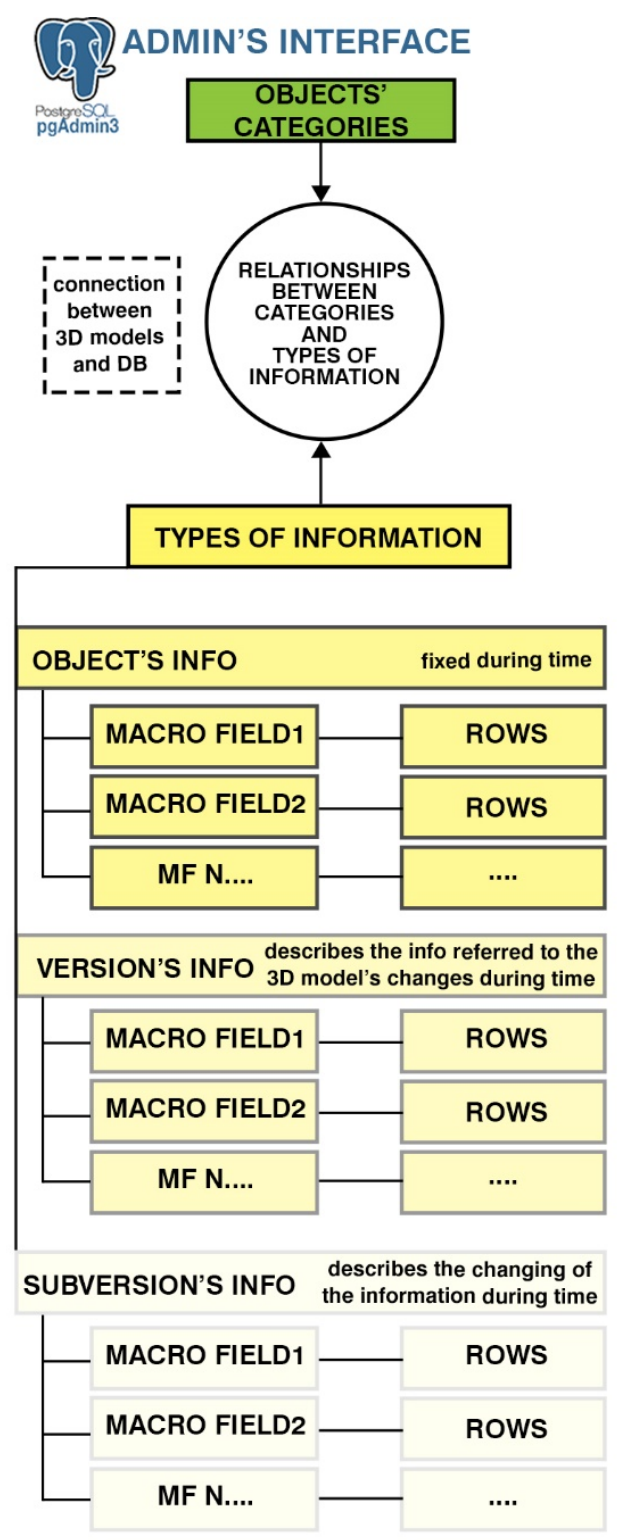

Figure 1. The scheme of the system's architecture: the categories assigned to $3 \mathrm{D}$ models are connected to the $\mathrm{DB}$ through relationships; the DB contains three typologies of information: object, version, and subversion. Each of these types is divided in macro fields (e.g. 3D model origin, cartographic origin, wall type, plaster, conservation story, construction typology, roofs monitoring, decay phenomena, diagnostic analyses, monitoring, natural context, water gathering, and others) and each macro field contains specific rows about that topic (e.g. for roof monitoring macro-field: the date of the survey, operator, material, description, the state of health of the roof, urgency of intervention, and notes).

3.2.1 Admin and User Interface: The structure of the database just described has a user interface inside the web browser Mozilla Firefox, at the following website: http://sacrimonti.bim3dsurvey.it. The model can be imported in different LODs to guarantee the use also in low-performance hardware (tablets and smartphones).

The visualisation goes from general to particular (Figure 2): in the first page it is possible to choose the Region (Piedmont or Lombardy), the Sacro Monte (Varallo, Oropa, Crea, Orta, Domodossola, Ghiffa, Belmonte, Ossuccio, Varese), the single

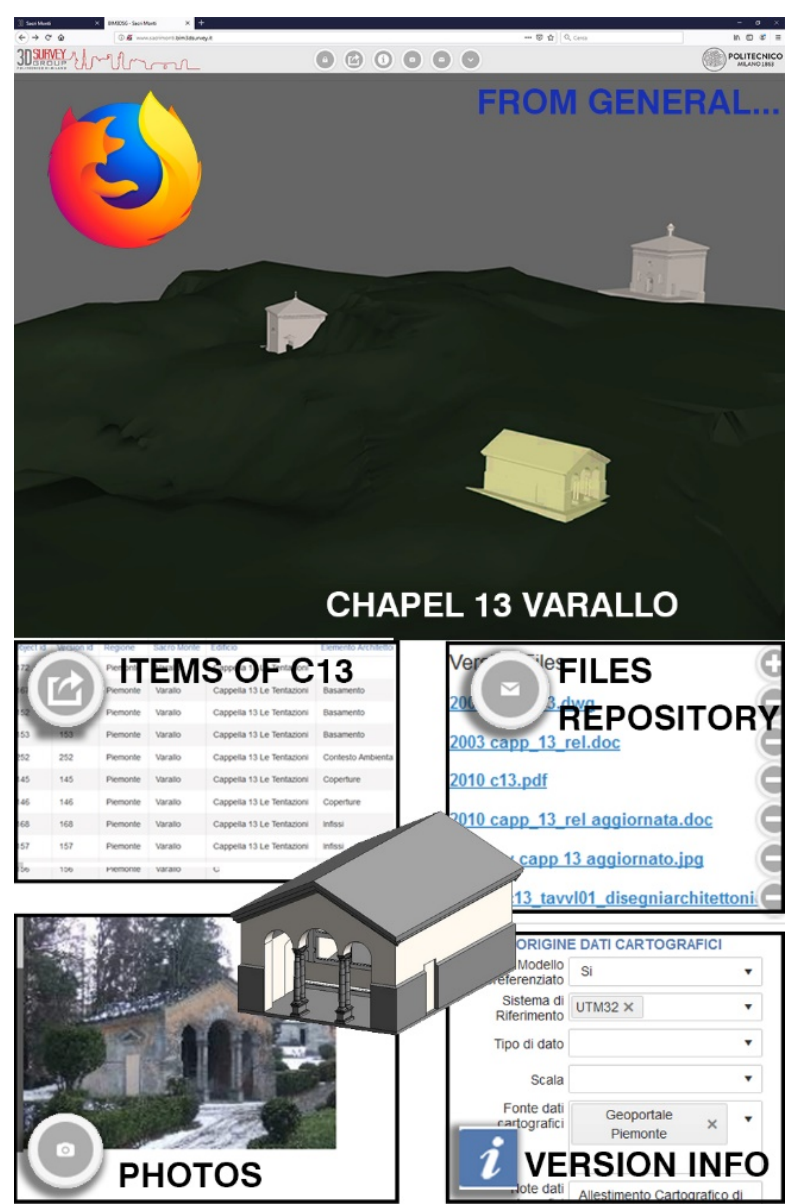

TO PARTICULAR...

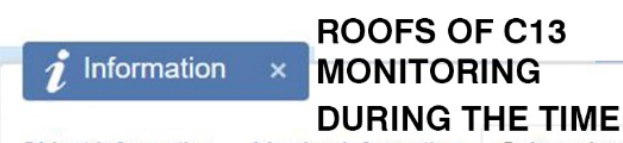

Object information Version information Subversion information

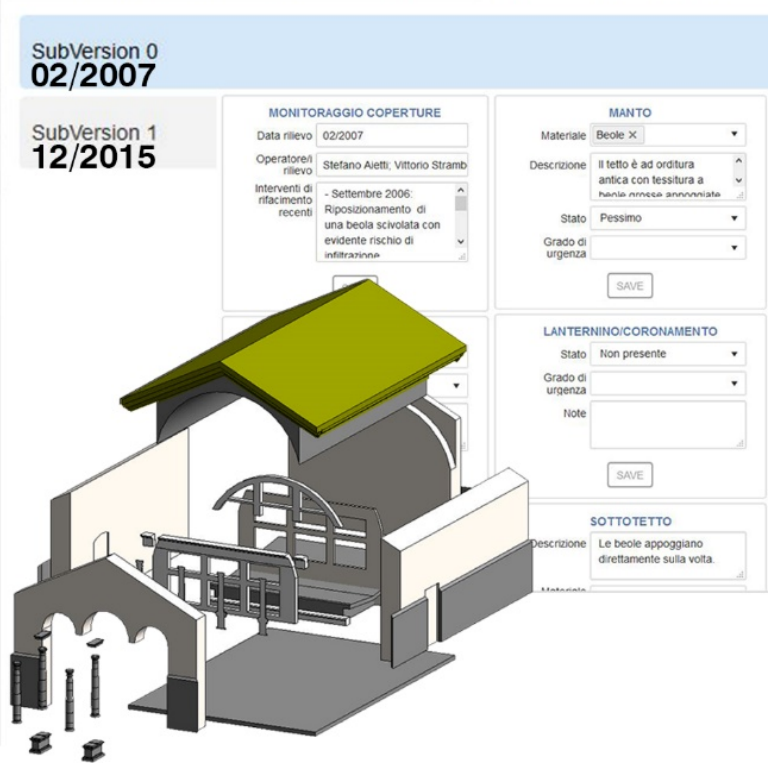

Figure 2. The logic of the system goes from general to particular, connecting a different kind of information to 3D models depending on the category imported. 
chapel, and architectural element. In this way, it is possible to upload or the specific single object (e.g. a column) or the entire building (e.g. Chapel 13 Varallo).

Moreover, the system lets to save and store different data as digital documents, 3D models, video, images, and more for their consultation inside the web environment. In particular, to each model were attached the original relations in the format at disposal from the Ente (standard report mainly in PDF format). Therefore, BIM3DSG becomes also as an archive, where to store all the documents related to the past interventions and monitoring of the Chapels.

The first data inserted were samples, the complete integration and assimilation of the information are on the Ente di Gestione dei Sacri Monti, after a training given by Politecnico staff, which consider its priority to create new expertise and knowledge, making people capable and independent to continue the monitoring activities. There were arranged username and password for Ente di Gestione that let the operations of reading and writing of the $\mathrm{DB}$, for directly managing the $3 \mathrm{D}$ models and the information.

Summarising, the system logic is to have a 3D model "zero" (made by multiple objects) that represents the first description and time threshold of the chapels (Figure 3). The operator links all the available technical sheets, photos, and documents and compiles all the information fields. When the Ente makes a new monitoring campaign (e.g. the control of the roofs), the system generates a sub-version of the model. So, the object remains the same - because its shape does not change - but the system makes a new copy that has the date of the new campaign, with blank fields to compile with the data updated.

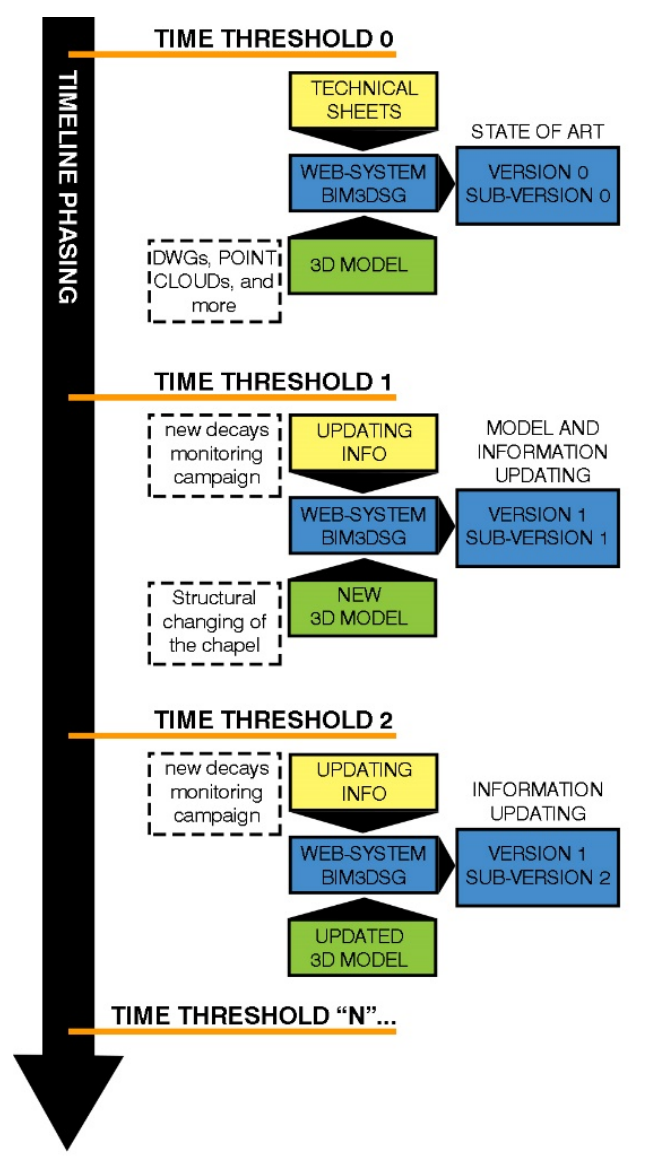

Figure 3. BIM3DSG time phasing: Threshold 0 is the existing condition of the chapel, with 3D model and information. In the Threshold 1, there is an updating both of the info and model, so they become version 1 and subversion 1 , and so on.
The older version of the information is stored in the same interface. Inside the layers, it is possible to recall models that belong to different times, according to the specific needs (e.g. if someone wants to extrapolate the chronology of the interventions on the roofs during one particular year). For example, Chapel 13 of Varallo is made by 27 objects (it is a small one), inside the level of the building - category building - it is possible to find the repository of the dwg files, the technical sheets, and the photo of the whole chapel. At the same time, the version info to compile comprehends the fields about the 3D model origin (typology of the data, date, source, modelling software, and operator), and the origin of the cartographic data (the geo-localisation of the model). The roofs of the Chapel - category roofs- contains the roofs monitoring fields in the subversion info (Table 2), with two different time thresholds (February 2007 and December 2015). Moreover, it is also possible to visualise the terrain model at the level of Sacro Monte - "Varallo"- and the chapels distributed in it. When it is possible or available, the Chapels also contains the original survey data (point cloud) as Chapel 2 of Domodossola, which includes the general point cloud of the site coming from Leica Pegasus Backpack, the building point cloud made both with Leica C10 TLS and both aerial and terrestrial photogrammetric point cloud (Tommasi et al., 2019).

\begin{tabular}{|c|c|}
\hline Macro fields & Rows \\
\hline \multicolumn{2}{|l|}{ Category: Roofs } \\
\hline \multicolumn{2}{|l|}{ Subversion Info } \\
\hline \multirow[t]{3}{*}{ Roof monitoring } & Date of survey \\
\hline & Survey operator/s \\
\hline & Recent interventions \\
\hline \multirow[t]{4}{*}{ Mantle } & Material \\
\hline & Description \\
\hline & State of health \\
\hline & Urgency \\
\hline \multirow[t]{3}{*}{ Lantern } & State of health \\
\hline & Urgency \\
\hline & Notes \\
\hline ... and others & $\ldots$ \\
\hline \multicolumn{2}{|l|}{ Category: Statues’ Groups } \\
\hline \multicolumn{2}{|l|}{ Object info } \\
\hline \multirow{8}{*}{$\begin{array}{l}\text { General information about } \\
\text { artefacts }\end{array}$} & Historic data \\
\hline & Author \\
\hline & Origin author \\
\hline & Date \\
\hline & Attribution \\
\hline & Inscription \\
\hline & Typology inscription \\
\hline & Localisation inscription \\
\hline \multirow[t]{3}{*}{ Building processes } & Support \\
\hline & Accessories \\
\hline & .....and more \\
\hline \multicolumn{2}{|l|}{ Subversion info } \\
\hline \multirow[t]{6}{*}{ Decay phenomena - furnitures } & Detachement \\
\hline & Delimitation detachement \\
\hline & State of detachement \\
\hline & Extension detachement \\
\hline & Urgency intervention \\
\hline & \\
\hline ....and others & $\ldots$ \\
\hline
\end{tabular}

Table 2. Example of some macro-fields and their relative rows inside the info of the roofs and statues' groups categories. E.g. for the roof category, under the subversion info, we find several macro-fields as roof monitoring, mantle, lantern and others. Under each macro-field there are the specific rows about it. 


\subsection{Future developments}

BIM3DSG is always in evolution, adapting its features to the case study, the users, and all the other factors that affect a project. That is why the system is still actual even if it was born in 2012. The work with Sacri Monti helped to develop some specific features, and the co-design process with Ente di Gestione highlights some implementations to carry out. Thanks to the work that Ente di Gestione is currently carrying on about the modelling and the insertion of data inside BIM3DSG, in a year the DB will have a high quantity of data inside it, which will let to structure the queries system. According to the technical office and the modalities of urgency indication for the interventions on the chapels, for some selected rows of specific categories (e.g. roofs), it is already visible the urgency level, defined through the score *, **, ***, ****. This parameter common to all the same categories of objects (e.g. roofs, walls, and others) makes the info extrapolation easier and efficient on-time interventions. In this way, in the future developments, the system will handle the queries, which need a recursive wording, e.g. "find all the roofs that have urgency of four stars". Another objective of this platform is to become more and more open to every type of users, and to conform to national and international legislation: in fact, its intrinsic features make BIM3DSG suitable to be a proper Common Data Environment (CDE). Common Data Environment is a methodology to handle the production, the distribution, and the quality of the information about the constructions. The website BIM Wiki describes it as "an online place as a single source for collecting, managing and sharing documentation, the graphical model and non-graphical data for the whole project team (i.e. all project information whether created in a BIM environment or a conventional data format)".

The national definition is contained in the norm UNI11337:3, which also describes the requirements and the objectives. In particular, the requirements are:

- $\quad$ accessibility from all the actors involved in the process following specific rules;

- traceability and time phases of the revisions to the contents;

- $\quad$ support of a wide range of formats and typology of data, and their elaborations;

- high interrogation flows and easy accessibility, recover, and extrapolation of data;

- $\quad$ conservation and updating during the time;

- warranty of security and privacy.

The objectives and the advantages of adopting a CDE are:

- $\quad$ automation in the information coordination between the subjects interested;

- $\quad$ authorship transparency and temporal availability of information;

- management automation of revisions and updating of the data;

- $\quad$ communication between affected parts through modules and reference interfaces.

The requirements and advantages just stated have many similarities with BIM3DSG system described above, and it is interesting to comparing its features with the ones of CDE, demonstrating that the future direction is to satisfy the national and international (British Standards Institute) legislation (Table 3).

${ }^{7}$ Extrapolation of data meant as the download of the previous reports stored in the file repository of BIM3DSG.

8 Participatory design means various forms of programs and activities where the participants are involved in the production process, by making, doing, or creating something, or contributing ideas to a project or work of art, regardless the skill

\begin{tabular}{|c|c|c|}
\hline \multirow{2}{*}{ FEATURES OF CDE } & \multicolumn{2}{|c|}{ BIM3DSG } \\
\cline { 2 - 3 } & Accomplished & In progress \\
\hline Online remote access to data & $\checkmark$ & \\
\hline $\begin{array}{c}\text { Accessibility of all the actors } \\
\text { involved }\end{array}$ & $\checkmark$ & \\
\hline $\begin{array}{c}\text { Traceability and time phases of } \\
\text { the contents' revisions }\end{array}$ & $\checkmark$ & \\
\hline $\begin{array}{l}\text { Support of a wide range of } \\
\text { formats and typology of data, } \\
\text { and their elaborations }\end{array}$ & $\checkmark$ & \\
\hline $\begin{array}{l}\text { High interrogation flows and } \\
\text { easy accessibility, recover }\end{array}$ & & $\checkmark$ \\
\hline $\begin{array}{c}\text { Conservation and updating } \\
\text { during the time }\end{array}$ & $\checkmark$ & \\
\hline $\begin{array}{c}\text { Warranty of security and } \\
\text { privacy }\end{array}$ & $\checkmark$ & \\
\hline Extrapolation of data & $\checkmark^{7}$ & \\
\hline
\end{tabular}

Table 3. The features of CDE are compared with the ones of BIM3DSG, highlighting what it is already capable of accomplishing, and what is still in progress.

\section{CONCLUSION}

The use of a sharing environment always updated and accessible in real time permits to exploit the advantages of BIM methodology, as the use of virtual models supported by an information DB, the automation of the coordination among experts with different background, and the conservation and updating during the time. BIM3DSG proposes an advanced strategy for managing the site activities of Ente di Gestione dei Sacri Monti, changing the traditional workflow and introducing a shared space where to store the data, visualise models, and compile the DB with the information agreed. The introduction of this method helps to update the Periodic Report of the third cycle, solving the need highlighted by the Second Cycle PR of a structured management and conservation plan. The strength of this tool is also that is was designed for Ente di Gestione, and with Ente di Gestione, shaping it on the real needs of the site and the users. The participatory ${ }^{8}$ design process (Figure 4) also responds to the necessity of local authorities and stakeholders' involvement, which always has a fundamental role in the valorisation of $\mathrm{CH}$ (UNESCO, MiBACT). Cultural access and participation is also an essential part of human rights as stated by the Council of Europe, and that is why this tool aims to be more and more democratic and open, avoiding to become obsolete in a short time, as it happens to most of the technological products nowadays. One of the ways to stay up to date is to not look only to the technical problem, but build a strategy that aims to solve problems considering all the factors involved: technology, people, context, and time. These activities give as a result good practices of an integrated valorisation, capable of defining tangible operational guidelines and raising the qualitative level of the interventions and the skills of the operator involved. The success of this kind of work is the capacity to stay topical and adapt to the new needs that can emerge during the time and to look at the specialists that work on site every day, creating a network, moments of ideas contamination, and training.

level. The degree of creative control varies from minimal (e.g., learning to do something), to maximal (e.g., choreographing something). The expressive nature of the activity is what makes it participatory, whether or not original work is created (Brown et al. 2011). 


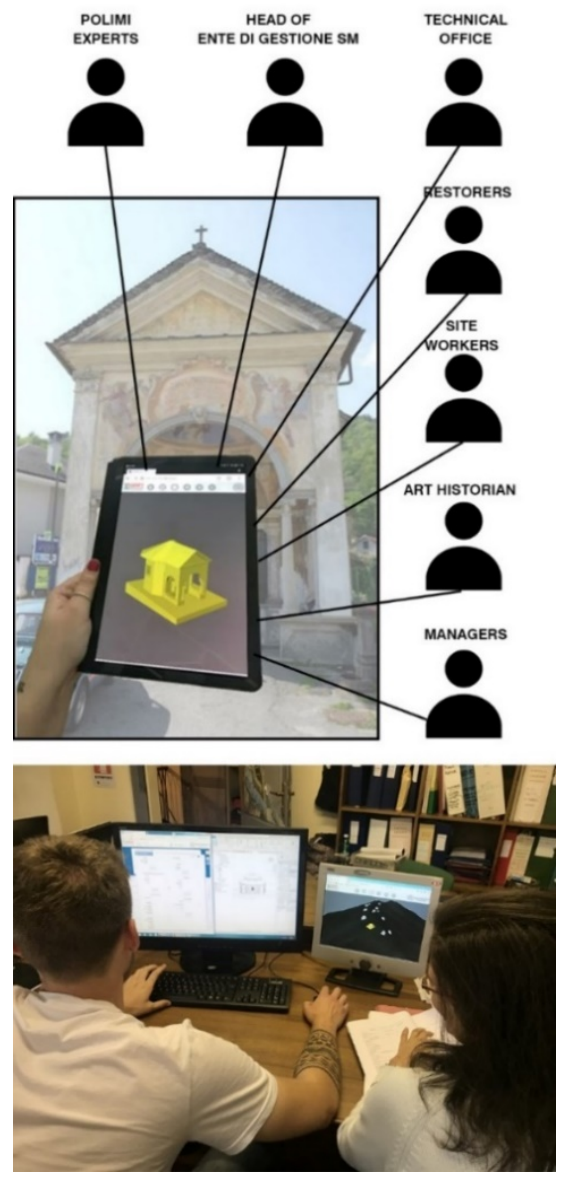

Figure 4. BIM3DSG connects experts' users with different backgrounds and gives the possibility to manage the models and information without the need for particular skills and software. Below, the specialists of Ente's technical office are using the system to insert the information about the chapels.

\section{ACKNOWLEDGEMENTS}

The authors want to thank all the technical office of Ente di Gestione dei Sacri Monti, in particular Elena Bellazzi and Michele Lotti for their patience and passion.

\section{REFERENCES}

Achille C., Fassi F., Mandelli A., Fiorillo F., 2018. Surveying Cultural Heritage: summer school for conservation activities, Applied Geomatics 10 (4), pp. 579-592, doi:10.1007/s12518-0180225-3.

BIM Wiki, https://www.designingbuildings.co.uk/. Last access: 06/2019.

Brown, G., Weber, D., 2011. Public Participation GIS: A new method for national park planning. In Landscape and Urban Planning, Ed. Elsevier, Volume 102, Issue 1, pp. 1-15, https://doi.org/10.1016/j.landurbplan.2011.03.003.

Council of Europe - COE, 2005. Convention on the Value of Cultural Heritage for Society, October 13, Faro, Portugal.

Decreto Legislativo 22 gennaio 2004, n. 42. Codice dei beni culturali e del paesaggio, ai sensi dell'articolo 10 Legge 6 luglio 2002, n. 137.
Della Torre, S., 2015. Lezioni imparate sul capo dei distretti culturali. In Il Capitale Culturale: Studies on the Value of Cultural Heritage, Vol. 03, pp. 61-73, doi: 10.13138/20392362/1175.

Ente di Gestione dei Sacri Monti, https://www.sacri-monti.com/. Accessed May 13 $3^{\text {th }}, 2019$.

Fassi F., Parri S., 2012. Complex Architecture in 3D: from survey to web. In International Journal of Heritage in the Digital Era 1, pp. 379-398.

ICOMOS International Council on Monuments and Sites. Retrieved from: https://www.icomos.org/. Accessed 18 March 2019.

Laing, R., 2018. Digital Participation and Collaboration in Architectural Design, 1st ed., Routledge, Oxon, UK.

MiBACT, Ministero per i Beni e le Attività Culturali, http://www.beniculturali.it/mibac/export/MiBAC/index.html, last access: 06/2019.

Mattelmäki, T., Sleeswijk Visser, F., 2011. Lost in Co-X: Interpretations of Co-Design and Co-Creation. In L-L. C. Norbert Roozenburg (Ed.), Proceedings of IASDR'11, 4th World Conference on Design Research, Delft University, International Association of Societies of Design Research (IASDR), pp. 1-12.

Negrini, M., Di Blas, N., 2015. Digital storytelling for Cultural Heritage: a Modular, Multi-channel. Multi-scenario Approach. In: Built Heritage: Monitoring Conservation Management, eds. Toniolo L., Boriani, M., Guidi, G., pub. Springer, pp. 781-788, doi: 10.1007/978-3-319-08533-3_31.

BSI, 2014. Publicity Available Specifications -PAS- 1192-3: Specification for information management for the operational phase of assets using building information modelling.

Rechichi F., Mandelli A., Achille C., Fassi F., 2016. Sharing high-resolution models and information on web: The web module of BIM3DSG system. In Int. Arch. Photogramm. Remote Sens. Spatial Inf. Sci., XLI-B5, pp. 703-710, doi:10.5194isprsarchives-XLI-B5-703-2016.

Tommasi C., Fiorillo F., Jiménez Fernández-Palacios B., Achille C., 2019. Access and web-sharing of 3D digital documentation of environmental and architectural heritage. In Int. Arch. Photogramm. Remote Sens. Spatial Inf. Sci., XLII-2/W9, pp. 707714, doi:10.5194/isprs-archives-XLII-2-W9-707-2019.

UNESCO, 1972, November 21. Convention Concerning the Protection of the World Cultural and Natural Heritage.

UNESCO, 2005, revised version 2017. The Operational Guidelines for the Implementation of the World Heritage Convention.

UNESCO, 2003. Document of Sacri Monti’s Nomination.

UNESCO, 2012. Handbook for Sites Managers.

UNESCO, 2014. Periodic Report, Second Cycle.

UNI 11337, 2017, January 26. Building and civil engineering works. Digital management of the information process in the construction field. 